\title{
A Ética do Desenvolvimento e a Proteção às Condições de Saúde ${ }^{1}$
}

\section{The Ethics of Development and Protection to Health Conditions}

\author{
Paulo C. Sabroza ${ }^{2}$ \\ Maria do Carmo Leal ${ }^{2}$ \\ Paulo M. Buss ${ }^{2}$
}

\section{SABROZA, P. C.; LEAL, M. do C. \& BUSS; P. M. The Ethics of Development and Protection to Health Conditions. Cad. Saúde Públ., Rio de Janeiro, 8 (1): 88-95, jan/mar, 1992.}

This article discusses the influence of the Brazilian development model on the environment and on the population's health, focusing on the major characteristics as well as the consequences of this model - the so-called eco-inequalities. This paper presents data that attempt to illustrate the relationships between development, environment and health.

The economic crisis of the last decade and the move to a neoliberal model by the Brazilian State are seen as factors that strongly hamper investments in the social and public sectors, promoting huge losses for the population and increased social inequalities in the country. Finally, emphasis is given to the need for a new ethics in the relationships among individuals, between individuals and State, and among Nations.

Keywords: Public Health; Environment; Development Models; Ethics; Health Conditions

\section{ÉTICA E DESENVOLVIMENTO}

A crise global do modelo de desenvolvimento capitalista repercute em todas as formações econômico-sociais, com impacto sobre a qualidade de vida e do ambiente.

O modelo de desenvolvimento econômico implantado na América Latina no pós-guerra, do ponto de vista da acumulação de capital, obteve resultados surpreendentes. No Brasil, o PIB duplicou em 18 anos, enquanto nos EUA o mesmo resultado foi alcançado no espaço de 47 anos, e na Inglaterra, em 59 anos.

Este desenvolvimento, que na sua primeira etapa se fez através do modelo do Cepal de substituição de importações, com abertura do mercado ao capital industrial internacional,

\footnotetext{
${ }^{\prime}$ Artigo originalmente preparado como contribuição ao documento do Brasil para a Conferência das Nações Unidas sobre o Meio Ambiente e Desenvolvimento (Rio-92) e modificado após discussão entre os autores para publicação neste periódico.

${ }^{2}$ Escola Nacional de Saúde Pública. Rua Leopoldo Bulhões, 1480, Rio de Janeiro, RI, 21041, Brasil.
}

estendeu-se por um período muito superior às suas possibilidades. Em grande parte, pela não realização das reformas estruturais de base, agrária, educacional e fiscal, indispensáveis ao prosseguimento do desenvolvimento econômico, em decorrência dos compromissos políticos das elites nacionais conservadoras.

Em um segundo momento, já no período autoritário, a acumulação prosseguiu e até mesmo se acentuou, através de mecanismos de poupança interna forçada, como a desvalorização salarial, indução da inflação e endividamento externo.

A modernização incompleta da indústria implicou na perda de sua competitividade e na necessidade de manutenção de subsídios.

Este modelo de financiamento teve sérias conseqüências para as condições de vida da população, agravando a concentração de renda $\mathrm{e}$ as desigualdades sociais.

Politicas sociais compensatórias foram promovidas nas áreas de seguridade social, assistência médica, distribuição de alimentos, saneamento, habitação. Se, por um lado, elas ajudaram a diminuir o impacto da perversidade do 
modelo sobre os grupos excluídos, por outro, contribuíram para a reprodução do processo de acumulação através da criação de mercado de consumo interno, articulado com a economia internacional.

A tentativa atual de ajuste do modelo coincide com a interrupção do financiamento externo e a renegociação da dívida, induzindo a uma crise sem precedentes (Cepal, 1991).

Se é evidente a responsabilidade das estruturas econômicas e políticas nacionais nos impasses do projeto de desenvolvimento, há também que se acentuar o papel determinante das políticas dos países de economia central sobre um conjunto de opções decisivas:

- $\mathrm{O}$ apoio às forças políticas conservadoras que impuseram o autoritarismo e impediram as reformas estruturais necessárias.

- O incentivo ao endividamento externo, financiando a manutenção do projeto político autoritário e, posteriormente, modificando os acordos financeiros, resultando em transferência maciça de capital da América Latina para os países centrais.

- A manutenção de barreiras de proteção comercial, dificultando a exportação de produtos brasileiros.

- A restrição à difusão de tecnologias avançadas através da utilização de registros de patentes e limitação do acesso ao conhecimento científico.

- A atração de recursos humanos selecionados da América Latina, impossibilitando o desenvolvimento de um conhecimento autônomo.

O modelo de desenvolvimento global foi incapaz de dar conta da diminuição da pobreza e acentuou as desigualdades (Dumont, 1989). A produção da desigualdade parece mesmo ser uma característica fundamental do modelo, na medida que possibilita a mobilidade do capital necessário à continuidade da acumulação (Smith, 1988).

Por outro lado, com o desenvolvimento das forças produtivas, a questão central do processo desloca-se da produção para a distribuição e o consumo. As políticas econômicas, entretanto, se mostram mais voltadas para atender aos interesses de setores da produção do que às necessidades fundamentais dos consumidores.

Entre os setores que foram privilegiados, destaca-se a produção de armamentos. Recentemente, esta produção bélica de alta tecnologia mostrou sua eficácia em ações coercitivas, caracterizando-se a presença de um poder de policia internacional que assegura a hegemonia através da força (Lacoste, 1991).

Outra modalidade estratégica de controle social foi o domínio sobre os instrumentos de comunicação coletiva. Deste modo, o controle da mídia internacional e dentro de cada país direciona a demanda para produtos supérfluos e assegura a distribuição desigual das informações, atuando como instrumento de alienação e dificultando a construção da cidadania.

Uma nova característica do atual modelo é a dissociação entre o crescimento econômico e o desenvolvimento social. A expansão das forças produtivas não parece mais estar condicionada à progressiva melhoria das condiçōes de educação, saúde e trabalho, como anteriormente parecia indiscutivel.

Um conjunto de indicadores de qualidade de vida e de saúde apontam que, mesmo nos países de economia central, o modelo de desenvolvimento não foi capaz de assegurar as condições de bem estar que a acumulação de recursos materiais possibilitaria.

Em diferentes momentos, a crise do modelo de desenvolvimento global tem sido confundida com seus limites setoriais, como o esgotamento dos recursos naturais não renováveis, o crescimento demográfico e, atualmente, a questão ambiental.

A responsabilidade sobre esses impasses tem sido sempre transferida para os países de economia periférica, apontando para a inviabilidade da extensão do modelo dominante para as formações econômico-sociais dependentes.

Cabe questionar não apenas a viabilidade da extensão desse modelo injusto e excludente, mas principalmente sua generalização como objetivo a ser perseguido por todos os povos.

Discule-se agora a necessidade de uma nova ética para o desenvolvimento.

Um novo modelo de desenvolvimento não pressupõe a ausência de crescimento econômi$\mathrm{co}$, mas o seu direcionamento para atender às necessidades das pessoas em termos de qualidade de vida.

O conceito de saúde articulado com este 
modelo precisa ser diferente do atual, contemplando outras dimensões de vida humana, inclusive suas interações com um ambiente protegido e não apenas dominado pelas relações econômicas.

Movimentos recentes de descentração econômica e de crescimento de núcleos urbanos autônomos, distanciados das grandes regiões metropolitanas, apontam para a viabilidade de propostas que parecem contrárias às tendências anteriores.

Estes comportamentos parecem resgatar a possibilidade de modos de vida com integridade e autonomia, sem perda de produtividade. Sua viabilidade depende fundamentalmente do acesso à informação diversificada, atualizada e eficaz.

Uma nova ética passa pela valorização da informação, considerando o indivíduo não apenas como receptor, mas garantindo o acesso ao conhecimento acumulado pela sociedade. Informação dirigida para o desenvolvimento de estratégias de produção autônomas e não para definir padrões de consumo.

Uma nova ética pressupõe também um mundo integrado, mas que assegure o direito à diversidade em relação aos processos econômicos, culturais e ambientais.

Uma nova ética implica em compromisso com a democracia, significando este conceito um novo modo de relação entre os indivíduos, e destes com o Estado, e uma outra ordem internacional (Rodrigues, 1991).

Para que a nova ética não seja apenas uma utopia, mas o fundamento para um outro modelo de desenvolvimento, é indispensável a superação do nível de miséria e de falta de instrução de grande parte da população, que impede a sua inserção efetiva no processo econômico e político e, portanto, o controle sobre suas condições concretas de existência, pressuposto da cidadania.

Os ajustes inevitáveis na conjuntura atual para as crises políticas, econômicas e ambientais não podem resultar em um estreitamento de possibilidades de transformações estruturais, comprometendo o futuro, e sim tem que considerar a necessidade, e possibilidade, da fundação de uma nova ordem.

\section{DESENVOLVIMENTO,}

\section{ECO-DESIGUALDADES E PROTEÇÃO À SAÚDE}

O modelo de desenvolvimento brasileiro tem aprofundado a desigualdade entre os grupos populacionais, não só segundo sua inserção diferenciada no processo produtivo, mas também de acordo com sua localização geográfica.

Uma das consequiências da distribuição acentuadamente desigual dos resultados do trabalho coletivo foi a produção de espaços também desiguais, acentuando diferenças entre regiōes geopolíticas e, no interior destas, entre as áreas rurais e urbanas, entre pólos econômicos e áreas descapitalizadas (Smith, 1988).

As dimensōes do pais e a diversidade de regiões e grupos sociais com tradições culturais próprias são determinantes na delimitação do cenário onde se dá o processo de modernização incompleta da economia e da sociedade, possibilitando a superposição das diversidades ecológicas e culturais - valores positivos enquanto expressões de vida - com as desigualdades sociais e a agressão ambiental, que negam aqueles valores e refletem processos que impōem os interesses de alguns sobre os da coletividade.

Este modelo de desenvolvimento tem como exigência e consequiência a articulação econômica e social dos espaços diferenciados, as eco-desigualdades.

A integração destes espaços diferenciados instalou-se de modo acelerado nos anos setenta, através da construção de eixos rodoviários e da extensão da rede de comunicações até os lugares mais distantes, sob a hegemonia de um modelo econômico e político autoritário (Becker, 1991).

O território nacional caracteriza-se, então, por uma fragmentação de diversidades, que são a expressão de recursos naturais e culturais particulares, mas também do acesso diferenciado aos produtos do desenvolvimento e investimentos sociais: o espaço desigual integrado.

A dinâmica da economia, centrada em alguns pólos de maior dinamismo, e a vontade dos indivíduos de lutarem por sua sobrevivência e melhores condições de vida colocaram em ação poderosas forças sociais. 
Grupos sociais inteiros, submetidos a constrangimentos em consequiência das dificuldades de acesso à terra, relações de trabalho não protegidas efetivamente e limitações de educação e conhecimentos adequados às novas práticas produtivas que se impõem, passaram a ter acesso, através dos veículos de comunicação de massa, a novos objetos de desejo. As condições de circulação espacial viabilizaram a urbanização acelerada e a pressão populacional sobre áreas com baixa densidade demográfica e ambiente ainda preservados, principalmente no Centro-Oeste e Amazônia.

$O$ grande fluxo migratório não resulta no assentamento da população. Ao contrário, as condições de trabalho e de uso e posse da terra fazem com que os deslocamentos iniciados sejam seguidos por uma mobilidade continuada.

Uma fração crescente da população brasileira passa a não integrar o circuito principal da economia, aquele que se moderniza e aumenta sua articulação com o mercado mundial (Santos, 1979).

Mobilidade e pauperização contribuem de modo determinante para o desgaste das condições de saúde e dificultam a consolidação dos direitos de cidadania, fundamentais para a concretização da proteção à saúde e ao ambiente.

A prioridade dada ao desenvolvimento de certos setores da economia e a falta de instrumentos de controle por parte da sociedade conduziu à utilização de procedimentos e produtos de risco, muitas vezes contrariando normas de segurança conhecidas.

O uso extensivo de agrotóxicos na produção de alimentos, a exposição ao benzeno em diversos setores da indústria e a ampla utilização de mercúrio na extração de ouro em garimpos são apenas três dentre numerosos exemplos de riscos para a saúde de trabalhadores ou consumidores, resultantes da utilização imprópria de insumos em processos de trabalho implantados durante esse período.

A freqüência com que são observados acidentes no transporte e manuseio de substâncias químicas tóxicas indica mais uma vez o risco da modernização incompleta, ou seja, da absorção de tecnologias e utilização de produtos sem o domínio adequado dos processos e sem o controle social necessário.

O desenvolvimento e valorização recentes das políticas de vigilância sanitária e de saúde do trabalhador exemplificam o reconhecimento da urgência desta modalidade de intervenção do Estado, em sua função de proteção à saúde, mas não parecem ser suficientes enquanto a produção econômica, subordinada a interesses particulares internos e externos, predominar sobre o interesse social.

É necessário ter o indivíduo como interlocutor e ator importante no controle destes processos, juntamente com o Estado e os grupos econômicos interessados, através de políticas de defesa dos direitos do consumidor e da valorização da cidadania. A distribuição desigual do acesso às informações e ao poder de decisão são obstáculos que tem limitado apenas a determinados grupos as possibilidades de ação política e social.

As audiências públicas nas avaliações dos riscos para a saúde, incluídas nos relatórios de impacto ambiental (RIMA's), precedendo obras que introduzem modificações relevantes no espaço natural e social são um exemplo da possibilidade de articulação da ação do Estado e dos grupos sociais organizados na proteção às condições de saúde.

Desta forma, é possível extender a discussão dos custos ambientais e sociais, dirigida inicialmente apenas para os resultados imediatos das obras de engenharia, também para as conseqüências da transformação do espaço para os diversos grupos sociais envolvidos, consolidando o conceito de custo social do desenvolvimento econômico.

Com o processo de democratização foram criadas as condiçôes para que se iniciasse um amplo debate, com participação de diferentes segmentos da sociedade, sobre a necessidade de reformular o Sistema Nacional de Saúde. Propõe-se a universalização do acesso, maior efetividade das ações de proteção e atenção à saúde e maior participação da comunidade no controle social destas práticas.

No modelo em implantação, procura-se atribuir maiores responsabilidades aos municipios, priorizando-se o desenvolvimento de sistemas locais de saúde (Teixeira, 1989). 
Considerando-se a existência de aproximadamente 4500 municípios, espera-se que, nessa escala, sejam contempladas as diversidades de problemas e soluções, que refletem as condições de saúde de grupos sociais particulares integrados em seus ambientes.

Ao mesmo tempo, neste nivel poder-se-ia estabelecer a possibilidade da ação coletiva mais eficaz, por exigir uma menor acumulação de organização e poder.

Contraditoriamente, os processos econômico-sociais mais gerais, promovendo a alienação de grandes contingentes populacionais de seus contextos coletivos e ambientais, direcionam a representação das necessidades de saúde para a demanda de cuidados assistenciais.

A medicalização crescente dos diversos problemas da população transformou o Brasil em um dos maiores consumidores mundiais de medicamentos, insumos e equipamentos de atenção médica, comercializados e utilizados freqüentemente sem preocupação com os cuidados necessários, com conseqüências prejudiciais para os usuários e evidente perda de eficácia (Campos, 1991).

A justa demanda de atenção médica por parte de numerosos grupos sociais, até então excluídos do acesso a esses serviços, tem pressionado os sistemas locais, de modo que os recursos disponiveis têm sido dirigidos prioritariamente para atividades assistenciais, prejudicando a efetividade das ações de proteção coletiva à saúde.

Através de convênios, muitos recursos públicos acabam sendo transferidos para instituições com objetivos lucrativos. Deste modo, uma justaposição de interesses de grupos privados nacionais $\mathrm{e}$ internacionais da indústria de equipamentos, medicamentos e atenção médica transformam a questão da saúde em um mercado, que assegura o fluxo de grande volume de recursos financeiros.

Neste contexto, a possibilidade de atuação eficaz do Estado, definindo políticas, programas e práticas de proteção e atenção à saúde $\mathrm{e}$ saneamento e regulando os interesses do mercado, depende da possibilidade da ação política de grupos sociais organizados e, portanto, de acumulação de conhecimento, articulação e poder no nível local.

$\mathrm{Na}$ articulação entre o Estado Nacional e os níveis locais que o integram - e onde se explicitam a diversidades das situações ambientais, sociais e de saúde - situam-se as possibilidades e limites de atendimento das necessidades de populações particulares, diminuindo as eco-desigualdades.

A operacionalização desse modelo coloca para o Estado e para a sociedade brasileira a exigência do desenvolvimento de novas propostas de coordenação interinstitucional, capacitação de recursos humanos, gerenciamento, financiamento, sistema de informações e estratégias de controle social pela população (Galo et al., 1992).

A crise econômica - que já dura uma década e é resultado de mudanças da economia mundial - e as impressionantes transferências de recursos para o exterior visando o pagamento dos juros da divida externa, prejudicam acentuadamente a capacidade de investimentos econômicos e sociais no país, agravando as desigualdades e limitando severamente a aplicação de recursos na proteção à saúde e ao ambiente.

Programas anteriores de financiamento ao saneamento, à construção de habitaçōes e ao controle de endemias foram interrompidos ou prejudicados após conseguirem resultados importantes, mesmo tendo sido concretizados através de práticas discriminatórias e centralizadoras.

Os custos sociais da pauperização, do desemprego, do aumento da mobilidade, da desestruturação das famílias, da perda de referência cultural e de resolutividade dos serviços públicos já recaem pesadamente e de modo desigual sobre a sociedade brasileira.

$O$ aumento generalizado da violência, em suas diversas modalidades de expressão, é um resultado direto desses processos.

O próprio conceito de saúde, como valor positivo, passa a ser reavaliado quando a necessidade de garantir a conservação biológica do indivíduo e da família exige o desenvolvimento de estratégias de sobrevivência estranhas ao seu ambiente cultural.

Os indicadores de saúde de que dispomos não conseguem registrar a multiplicidade de perfis epidemiológicos dos diferentes grupos sociais que compõem a sociedade brasileira, mas apontam algumas tendèncias que refletem 
o resultado dos investimentos públicos realizados anteriormente ao período recessivo.

Nas últimas décadas, o acesso a serviços básicos de saneamento nas populações de cidades de médio e grande portes aumentou cinco vezes.

A transmissão intradomiciliar da doença de Chagas, que atingia uma população de mais de seis milhões de individuos, foi praticamente interrompida e as formas graves de esquistossomose foram muito reduzidas em todo o país através de programas especiais.

A mortalidade por doenças imunopreviníveis em crianças de 0 a 4 anos reduziu-se em mais de $50 \%$, enquanto a incidência de poliomielite e raiva humana desapareceu na maior parte das grandes cidades.

A rede instalada de serviços de saúde expandiu-se de 13.000 estabelecimentos, em 1975, para 33.600, em 1988 . Apesar disso, o setor público de internação ainda é extremamente vulnerável, pois possui somente $22,9 \%$ dos 527 mil leitos disponíveis no país.

Observou-se uma queda acentuada da natalidade, embora ainda não seja possível estimar com precisão sua magnitude ou de que maneira esta queda atingiu, de modo diferenciado, os vários grupos sociais.

Durante a década de oitenta, quando a recessão econômica se instalou, observou-se comportamento atípico de alguns indicadores de mortalidade. Assim, embora a mortalidade infantil ainda apresente valores incompativeis com o desenvolvimento do país, continua mostrando uma tendência declinante, sendo estimada, em 1980, em 75 óbitos por mil nascidos vivos e, em 1987, em cerca de 60 para o Brasil como um todo. Ainda hoje, em torno de $20 \%$ de todas as mortes no primeiro ano de vida guardam relação com condições ligadas ao saneamento ambiental (Oliveira, 1989).

A prevalência de desnutrição, avaliada em crianças menores de cinco anos em dois inquéritos domiciliares (1974 e 1989), diminuiu em $62,5 \%$ quanto às formas graves e moderadas $e$ $33,4 \%$ em relação a todas as formas (MS/Inan, 1989).

A dissociação entre os indicadores de qualidade de vida e de mortalidade infantil e desnu- trição é um dado recente que parece mostrar que diversos grupos sociais desenvolveram sstratégias particulares de sobrevivência, provavelmente utilizando serviços públicos de proteção à saúde.

Entretanto, persistem, e até mesmo aumentam, as diferenças entre regiões, entre populações urbanas e rurais e entre grupos sociais particulares. Isto reforça a tese de que, a despeito dos resultados globais, o modelo atual de desenvolvimento produziu, na realidade, no campo da saúde e do meio ambiente, todas as condições para que se instalem as chamadas eco-desigualdades.

Assim, no período 1980 a 1986, a probabilidade de morrer com menos de um ano de vida decresceu em 52,2\% na Região Metropolitana do Rio de Janeiro e em apenas $38,6 \%$ na Região Metropolitana de Recife.

A Pesquisa Nacional sobre a Saúde e $\mathrm{Nu}$ trição mostra que $41,6 \%$ das crianças de 0 a 5 anos da área rural brasileira têm algum grau de desnutrição, contra $25,7 \%$ da área urbana. Considerando-se as formas moderadas e graves, a freqüência de desnutrição foi 4 vezes maior na Região Nordeste do que no Sul-Sudeste (MS/Inan, 1989).

A despeito dos avanços, no Brasil urbano cerca de vinte milhões de pessoas ainda não têm acesso à água tratada; setenta e cinco milhões não dispõem de serviços de esgoto, e sessenta milhões não são atendidas por coleta de lixo. Apenas 3\% do lixo urbano têm disposição final adequada, $63 \%$ são lançados em cursos de água e $34 \%$, a céu aberto.

$\mathrm{Na}$ Região Amazônica, o recrudescimento da malária em anos recentes, com mais de $\mathbf{5 0 0}$ mil casos/ano, coincide com a ocupação descontrolada das novas fronteiras agrícolas, movimento que não se acompanha de aumento correspondente dos serviços de proteção à saúde (Bretas, 1988).

A queda da natalidade e o aumento da expectativa de vida, em conseqüência da diminuição da mortalidade infantil, apontam para um progressivo incremento da proporção de idosos na população brasileira, com o conseqüente aumento dos agravos próprios desta faixa etária e na conhecida repercurssão sobre os serviços de saúde (Veras, 1988). 
A mortalidade por câncer de pulmão, câncer de colo de útero e doenças cardiovasculares, que em outros países vem diminuindo, vem se mantendo ou mesmo aumentando no Brasil.

A mortalidade por acidentes e causas violentas tem importância crescente, sendo responsável, em 1985, por $11 \%$ do total dos óbitos, o segundo grupo mais importante dentre aqueles com causa definida.

A capacidade de sobrevivência das familias submetidas a condições de vida degradantes parece estar próxima de atingir os limites que a exploração de recursos naturais ou de recursos dos serviços públicos, em deterioração, puderam assegurar.

A violência generalizada e a difusão do uso de tóxicos podem ser considerados indicadores da crise social que a persistência das condições de desigualdade extrema, integrada espacial e socialmente, promove.

Outro indicador da crise na saúde, enquanto resultado da combinação do modelo de desenvolvimento desigual e integrado com a recessão imposta pela lógica da economia do mercado internacional, é o ressurgimento de situações epidêmicas de doenças, que a partir de 1974 , atingiram o Brasil e outros países da América Latina.

Não podem ser explicados apenas por determinações locais os aumentos da transmissão da malária, do dengue, dos surtos de leptospirose, de leishmaniose tegumentar e calazar, e, recentemente, do cólera, e mesmo a introdução da AIDS.

Doenças causadas por parasitas como a oncocercose, as arboviroses e a febre maculosa, que até então se apresentavam como de ocorrência limitada a focos bem definidos, passaram a se disseminar.

Taxas crescentes de hanseníase, tuberculose, hepatite e doenças sexualmente transmissiveis se superpōem ao padrão de diminuição da mortalidade na infância e envelhecimento da população.

Processos endêmicos-epidêmicos não podem mais ser justificados através da persistência de bolsões de pobreza, que retratam modos de vida anteriores ao desenvolvimento capitalista (Sabroza, 1991).

$\mathrm{Na}$ verdade, assim como a violência; a adição a drogas, os acidentes de trânsito e de trabalho e as intoxicações por pesticidas são resultados do processo de desenvolvimento, como vem sendo imposto à sociedade.

Deste modo, estes problemas não tendem a diminuir, mas, ao contrário, a aumentar, na medida que se acentuam as desigualdades, juntamente com a integração, produzindo a pauperização, a mobilidade, o desemprego e o acesso parcial a informações.

$\mathrm{O}$ conceito de proteção à saúde pode, em situações limites como a que se configura, ser assumido como barreira sanitária, divisão, apartheid, com risco de acentuar a discriminação e consolidar a desigualdade.

As formas de organização da sociedade civil diante do mercado induzem à constituição de grupos de pressão corporativista que lutam por seus interesses específicos, minimizando projetos que contemplem a solidariedade com o conjunto da população.

O Estado brasileiro, diante das limitações de possibilidades de financiamento e premido pela pressão de grupos de interesse, mostra-se cerceado na realização das suas funções de promover políticas de saúde e de controle ambiental, compativeis com as exigências de modernidade e da democratização da sociedade.

Se o Estado autoritário não foi capaz, nem pretendeu ser, de atender às necessidades de proteção e atenção à saúde da população, o Estado liberal dependente também não o será.

Por outro lado, a possibilidade de ampla circulação de indivíduos, equipamentos, capital e informações viabiliza atualmente, mais do que em qualquer outra época, novas formas de organização política e social que poderão assegurar as condições de diversidade, autonomia e interação ambiental como valores positivos, dentro de um modelo de desenvolvimento auto-sustentado.

Novas modalidades de relação entre Estado, grupos sociais e individuos terão que ser desenvolvidas, possibilitando a construção de modelos de proteção à saúde que contemplem a justiça social na diversidade, utilizando os recursos científicos e tecnológicos, patrimônio da humanidade, de modo a assegurar uma qualidade de vida que incorpore uma relação harmônica com o ambiente. 


\section{AGRADECIMENTOS}

Os autores agradecem as valiosas sugestões do Dr. Rodolfo Rodriguez, representante no Brasil da Organização Pan-americana da Saúde.

\section{RESUMO}

SABROZA, P. C.; LEAL, M. do C. \& BUSS, P. M. A Ética do Desenvolvimento e a Proteção às Condições de Saúde. Cad. Saúde Públ., Rio de Janeiro, 8 (1): 88-95, jan/abr, 1992.

Neste artigo discute-se a influência do modelo de desenvolvimento brasileiro sobre o meio ambiente e a saúde da população, apontando suas características centrais e suas conseqüências, as denominadas eco-desigualdades. Relaciona-se dados que procuram ilustrar as relações entre desenvolvimento, meio ambiente e saúde. Considera-se que a crise econômica da última década, bem como a aproximação do Estado brasileiro ao modelo neo-liberal, dificultam acentuadamente os investimentos nos setores sociais e públicos, antevendo-se enormes prejuízos para a população, com a acentuação das desigualdades sociais no pais. Enfatiza-se, por fim, a necessidade de uma nova ética nas relações entre os indivíduos, indivíduos e Estado e entre Nações.

Palavras Chave: Saúde Pública; Meio Ambiente; Modelos de Desenvolvimento; Ética; Condições de Saúde

\section{REFERÊNCIAS BIBLIOGRÁFICAS}

BECKER, B., 1991. Modernidade e gestão do território no Brasil: da integração nacional à integração competitiva. Espaço e Debate, 32: 47-56.

BRETAS, G., 1990. A determinação da malária no processo de ocupação da fronteira agrícola. Tese de Mestrado, Rio de Janeiro: Escola Nacional Saúde Pública.

CAMPOS, G. W. S., 1991. Saúde: uma politica para a vida. São Paulo: Hucitec.
CEPAL, 1991. El desarrollo sustentable: transformación productiva, equidad y medio ambiente. Publicação da Organização das Nações Unidas $n^{2}$ Doc LC/G 1648, Santiago do Chile: ONU.

DUMONT, R., 1989. Um mundo intolerável: $O$ liberalismo em questão. Rio de Janeiro: Revan.

GALO, E.; RIVERA, F. J. U. \& MACHADO, M. H. (org.), 1992. Planejamento criativo: novos desafios teóricos em políticas de saúde. Rio de Janeiro: Relume Dumará.

LACOSTE, Y., 1991. Contra os antiterceiro-mundistas e contra certos terceiros mundistas. São Paulo: Ática.

LAURENTI, R., 1990. Transição demográfica e transição epidemiológica. In: Anais do $1^{\circ}$ Congresso Brasileiro de Epidemiologia, pp. 143-165, Rio de Janeiro: Associação Brasileira de Pós-Graduação em Saúde Coletiva.

MS-INAN, 1989. Pesquisa Nacional sobre Saúde e Nutrição, Brasillia: Instituto Nacional de Alimentação e Nutrição.

OLIVEIRA, L., 1989. A mortalidade infantil e a dinâmica social. In: Perfil estatistico de crianças $e$ mães do Brasil. Rio de Janeiro: Fundação IBGE/Unicef.

RODRIGUES, R., 1991. La etica del desarrollo. Texto apresentado na reunião preparatória da Pré-Conferência de Saúde da Rio-92, promovida pela Fiocruz, Rio de Janeiro (Mimeo.).

SABROZA, P. C., 1991. Endemias: doenças antigas e novos processos. Tempo e Presença, 260: 5-7.

SANTOS, M., 1979. O espaço dividido (Os dois circuitos da economia urbana dos países subdesenvolvidos). Rio de Janeiro: Francisco Alves.

SMITH, N., 1988. Desenvolvimento desigual. São Paulo: Bertrand Brasil.

TEIXEIRA, S. F. (org.), 1989. Reforma Sanitária: em busca de uma teoria. São Paulo: Ed. Cortez.

VERAS, R. P, 1988. Considerações acerca de um jovem país que envelhece. Cadernos de Saúde Pública, 4: 382-397. 